\title{
STATUS OF AMBIENT PARTICULATE MATTER AND BLACK CARBON CONCENTRATIONS IN RAJSHAHI AIR, BANGLADESH
}

\author{
BILKIS A. BEGUM*, K. SHAHIN AHMED ${ }^{1}$, M. SARKAR ${ }^{1}$, J. B. ISLAM ${ }^{1}$ AND \\ A. K. M. LUTFOR RAHMAN ${ }^{1}$ \\ Chemistry Division, Atomic Energy Centre, P.O. Box 164, Dhaka-1000, Bangladesh
}

\begin{abstract}
Air borne particulate matter (PM) samples (both $\mathrm{PM}_{10}$ and $\mathrm{PM}_{2.5}$ ) were collected simultaneously from continuous air quality monitoring station (CAMS) at Rajshahi city from December 2012 to February 2013 using two Air Metrics MiniVol samplers. The samples were analyzed for mass and black carbon (BC) concentrations. The present results were compared with the data set during December 2001 to February 2002. It was found that the mean $\mathrm{PM}_{10}, \mathrm{PM}_{2.5}$ and BC concentrations have increased 3.3, 6.1 and 3.4 times, respectively than in December 2001 to February 2002 period. Similarly, the ratio of $\mathrm{PM}_{2.5} / \mathrm{PM}_{10}$ has increased twice than the previous cited time. In case of $\mathrm{BC} / \mathrm{PM}_{2.5}$ ratio, value becomes more than half than the previous period. Hence, $\mathrm{PM}_{2.5}$ concentration has increased tremendously and due to the implementation of policies especially on motor vehicles, $\mathrm{BC}$ concentration does not increase linearly as $\mathrm{PM}_{2.5}$. The present data have showed that about $78 \%$ of $\mathrm{PM}_{10}$ is $\mathrm{PM}_{2.5}$ whereas in $2001-2002, \mathrm{PM}_{2.5}$ was only $38 \%$ of $\mathrm{PM}_{10}$. The high $\mathrm{PM}_{2.5}$ at Rajshahi city might be due to both local effect and long-range transport.
\end{abstract}

Key word: $\mathrm{PM}_{2.5}, \mathrm{PM}_{10}$, Black carbon, Ambient particulate matter

\section{INTRODUCTION}

Rajshahi city is located in the northwest of the country (latitude $24.37 \mathrm{~N}$, longitude $88.70 \mathrm{E}$ ) and has an estimated population of 853,000 people. This city is situated near the border with India. Particles below $10 \mathrm{~m}$ correspond to the inhalable fraction of particulate matter and have been related to various adverse health effects. $\mathrm{PM}_{10}$ particle mass includes both fine (below $2.5 \mathrm{~m}$ ) and coarse (between 2.5 and $10 \mathrm{~m}$ ) fractions of airborne particulate matter which normally arise from different sources. Fine particles are mainly particles from combustion processes or are formed within the atmosphere by chemical processes. On the other hand, coarse particles generally arise from natural sources (wind-blown soil, sea spray, pollens) or from construction and quarrying activities. Pollutant dispersion mechanisms, depending both on the site topography and on the meteorological conditions strongly influence the concentrations of particles. The visible impact of air pollution is gaseous pollutants and particles from biomass burning,

*Correspondence: bilkisab@dhaka.net

${ }^{1}$ Department of Chemistry, Jagannath University, Dhaka-1100, Bangladesh. 
traffic, and industrial emission. Vehicle exhaust, coal based power plants near Indian borders (Rajshahi region), factory emissions, domestic wood, dung fires and smoke from the burning of forests are the sources of air pollution and add to the haze formation. Black carbon (BC) is an important constituent of airborne particulate matter (PM) that is often emitted as product of incomplete combustion (Koelmans et al. 2006). The two most important BC sources are fossil fuel combustion and biomass burning (Cooke and Wilson 1996, Penner et al. 1993). BC can act in two ways. First as a direct absorber of visible light that provides direct warming in the lower atmosphere. Secondly, the deposition of black carbon on ice or snow such as on Himalayan glaciers (Kehrwald et al. 2008) is part of what is causing them to rapidly melt. BC may also influence climate indirectly on a regional scale by altering the monsoon circulation and hydrological cycle. Thus, there are valid reasons to understand the extent and sources of BC. The main fuel sources at Rajshahi is the huge domestic wood and dung fires, twigs and leaves, rice husks, bagasse fiber derived from sugar production, jute stick etc. There are more than 30 brickfields around 7 - 8 kilometers of the city. All these are polluting air. Moreover, there are coal based power plants located at Indian border line near Rajshahi. During the winter time, the wind comes from the northwest direction. Due to the transboundary effect, local concentration of particulate matter and black carbon is increasing day by day in Rajshahi. As a result, various vital diseases such as asthma, lung cancer, respiratory diseases, birth defect, premature death etc. occur. The main objective of this study was to find out ambient fine PM and BC concentrations in air at Rajshahi city during winter months.

\section{MATERIALS AND METHOD}

Particulate matter samplings were performed using Air Metrics MiniVol samplers for collection both $\mathrm{PM}_{10}$ and $\mathrm{PM}_{2.5}$ samples from the Shalbagan site (Fig. 1) in Rajshahi city. Rajshahi is a hot site due to Rajshahi is the border district of Bangladesh. Moreover, there are coal-based power plants located at Indian border line near Rajshahi. During the winter time, the wind comes from the northwest direction. Due to the rise of transboundary effect and local effect the concentration of particulate matter and black carbon is increasing day by day at Rajshahi. As a result, various vital diseases such as asthma, lung cancer, respiratory diseases, birth defect, premature death etc. occur. At Rajshahi the samplers were placed on the roof of CAMS (Continuous Air Monitoring Station) building. Two types of filters one was Teflon $\left(\mathrm{PM}_{2.5}\right)$ and other Glass fiber $\left(\mathrm{PM}_{10}\right)$ for two different samples were used. The actual flow rate must be $5 \mathrm{~L} / \mathrm{min}$ at ambient conditions for proper size fractionation. To ensure a constant flow of $5 \mathrm{~L} / \mathrm{min}$ through the size separator at different air temperatures and ambient pleasure, the sampler flow rates were adjusted for the ambient conditions at the sampling site. The MiniVol samplers were positioned with the intake upward and located in an unobstructed area at 
list $30 \mathrm{~cm}$ from any obstacle to air flow and the sampler's inlet were placed at a height of $10 \mathrm{~m}$ above from the ground level for the Rajshahi site. The intake nozzles of the samplers at the Rajshahi location were about $5 \mathrm{~m}$ away from the main road. $\mathrm{PM}_{10}$ and $\mathrm{PM}_{2.5}$ were collected simultaneously from 8 a.m. to next day 8 a.m. with two MiniVol samplers. The inlets of the samplers were kept $45 \mathrm{~cm}$ apart from each other. The sampling protocol was every third day and it was forty five consecutive days starting from December 1, 2012 to February 27, 2013. The conditioned clean filters were loaded to respective filter holder assembly at the CAMS conditioning room and were brought to sampling site in separate clean polyethylene bag at each effective sampling day. After sampling, the filter holder assemblies from the sampling site for conditioning and PM retrieval. Volvo bus was taken in transporting the exposed filter holder assemblies, so that there should be no PM and BC loss.

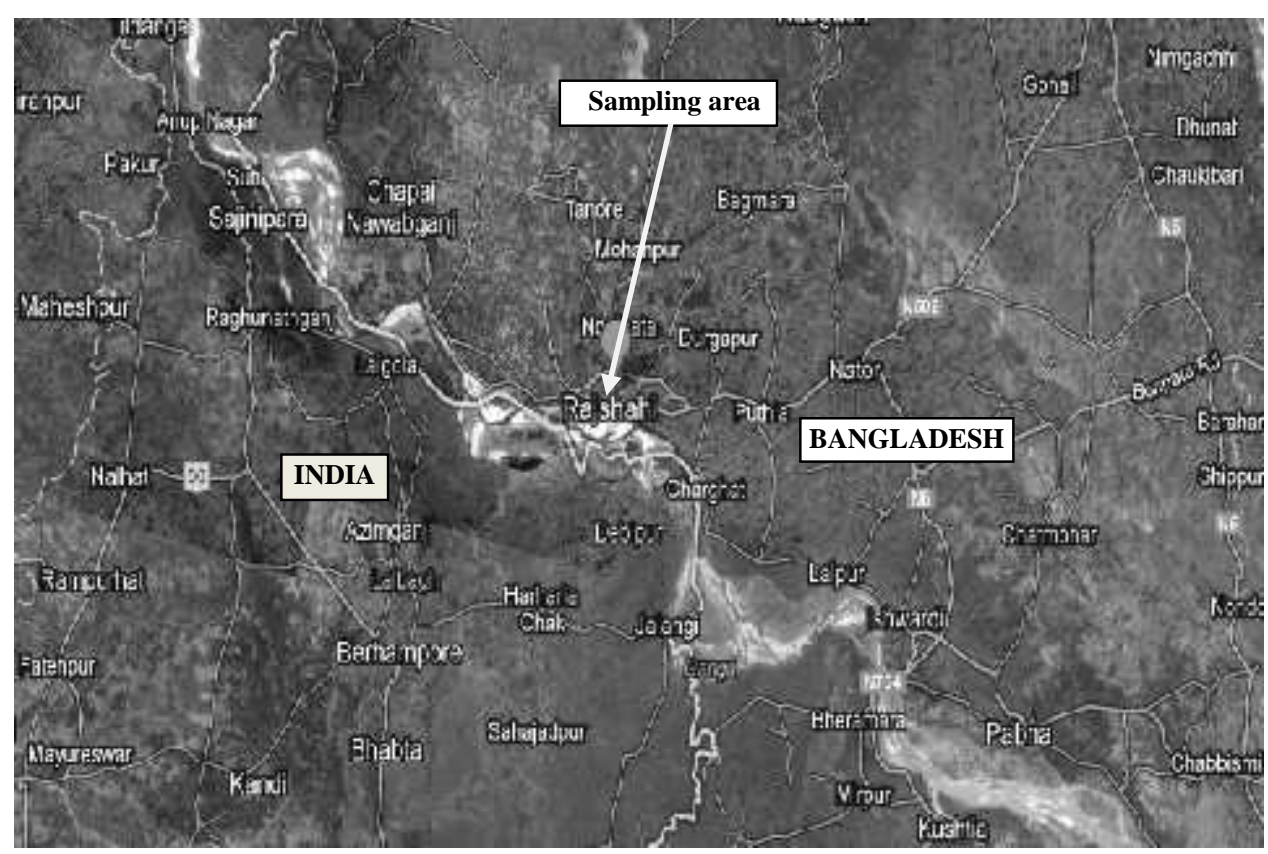

Fig. 1. Map of sampling location.

In Bangladesh, the climate is characterized by high temperatures, high humidity for most of the year and distinctly marked seasonal variations in precipitation. According to meteorological condition (Salam et al. 2003), the year can be divided into four seasons, pre-monsoon (March-May), monsoon (June-September), post-monsoon (OctoberNovember) and winter (December-February). As the dispersion of fine PM strongly depends on the wind speed and direction, meteorological data for dates of samples collection were made from Bangladesh Meteorological Department (BMD) the 
meteorological station, which is located at Dhaka. The wind direction pattern at Rajshahi city is given in Fig. 2.

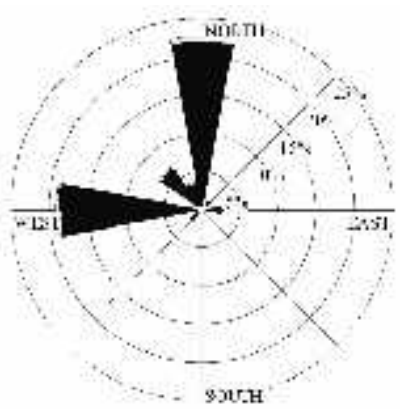

Winter

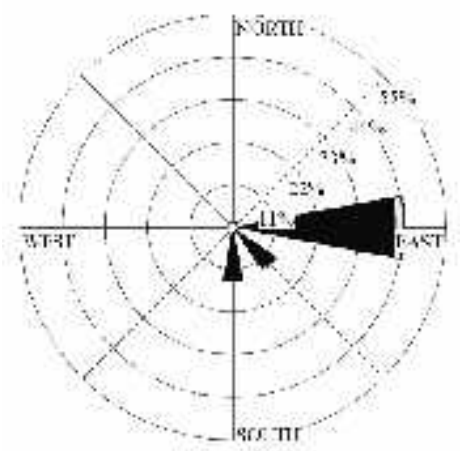

Monsoon

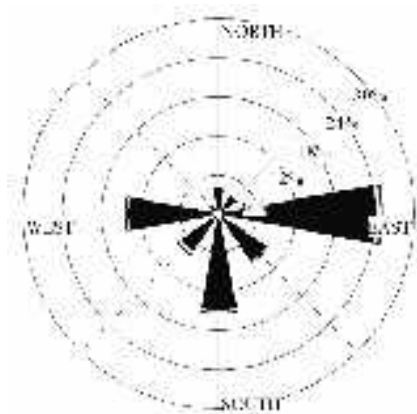

Pre-monsoon

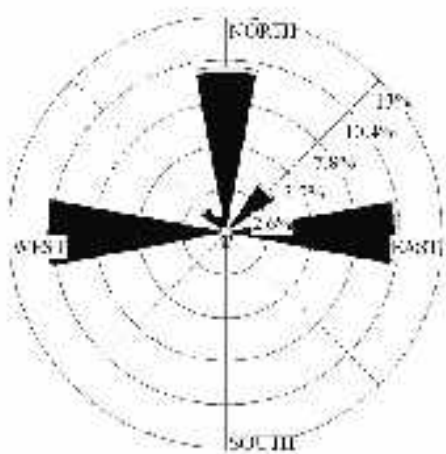

Post-monsoon

Fig. 2. Wind direction pattern for Rajshahi city.

PM Mass was measured in the Chemistry laboratory of the Atomic Energy Centre, Dhaka (AECD). The $\mathrm{PM}_{10}$ and $\mathrm{PM}_{2.5}$ samples were determined by weighing the filters before and after exposure using a microbalance (Begum et al. 2006a). The filters were equilibrated for $24 \mathrm{hrs}$ at constant humidity of $50 \%$ and temperature $\left(22^{\circ} \mathrm{C}\right)$ in the balance room before every weighing. A Po-210 (alpha emitter) electrostatic charge eliminator was used to eliminate the static charge accumulated on the filters before each weighing. The difference in weights for each filter was calculated and the mass concentrations for each $\mathrm{PM}_{10}$ or $\mathrm{PM}_{2.5}$ samples were determined.

The concentration of $\mathrm{BC}$ in the $\mathrm{PM}_{10}$ and $\mathrm{PM}_{2.5}$ samples were determined by reflectance measurement in AECD laboratory using an Electroselenium Limited (EEL) type Smoke Stain Reflectometer (Biswas et al. 2003). Secondary standard of known black carbon concentration was used to calibrate the reflectometer. The concentrations 
are defined based on the amount of reflected light that is absorbed by the filter sample and an assumed mass absorption coefficient. It is related to the concentration of light absorbing carbon through standard carbon with known areal density. Iron $(\mathrm{Fe})$ has a moderate light absorption coefficient and can have some limited influence on the BC value measured by reflectance. The uncertainty associated with the $\mathrm{BC}$ measurement is rather high (4-9\%), and therefore, the influence of variation in $\mathrm{Fe}$ concentration on $\mathrm{BC}$ measurement has been neglected.

\section{RESULTS AND DISCUSSION}

Rajshahi has witnessed a rapid growth of urban population and industrialization in recent times, which contributed to rising demand for transport services, mainly road transport. As a result, the number of motor vehicles increases gradually in Rajshahi. There has been a steep rise in a heterogeneous mixture of old technology vehicles despite that the road space narrowing and the traffic congestion reaching unmanageable proportions. As a result, major traffic intersections in the city have turned to hot sports for air pollution from vehicular emissions. About two hundred thousand tons air pollutants are emitted yearly from motor vehicles (Kundu et al. 2006).

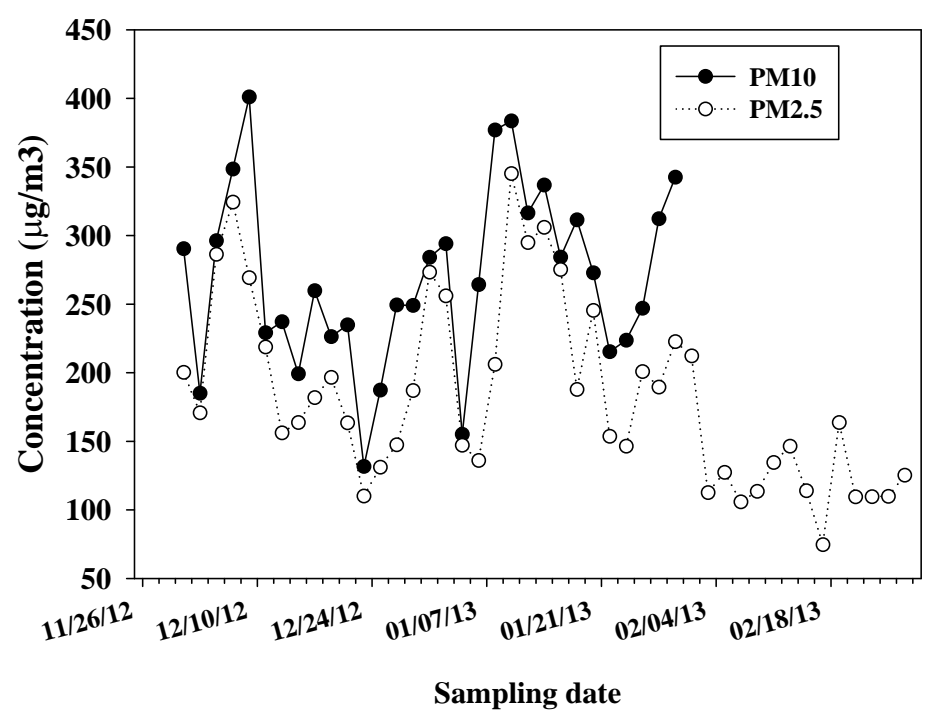

Fig. 3. Variation of the daily average value of $\mathrm{PM}_{10}$ and $\mathrm{PM}_{2.5}$ from December 01, 2012 to February 28, 2013.

During the study period, the daily $\mathrm{PM}_{2.5}$ and $\mathrm{PM}_{10}$ concentrations (Fig. 3) were higher than the $24 \mathrm{~h}$ average Bangladesh National Ambient Air Quality Standard (BNAAQS), which were set at 65 and $150 \mathrm{~g} / \mathrm{m}^{3}$, respectively. The statistics of PM and BC concentrations during the sampling periods is given in Table 1 . 
Table 1. Basic statistics of $\mathbf{P M}_{10}, \mathbf{P M}_{2.5}, \mathrm{BC}$ concentrations and their ratios during the sampling periods December, 2012 to February, 2013.

\begin{tabular}{lccccc}
\hline Parameters & $\begin{array}{c}\mathrm{PM}_{10} \\
\left(\mu \mathrm{g} / \mathrm{m}^{3}\right)\end{array}$ & $\begin{array}{c}\mathrm{PM}_{2.5} \\
\left(\mu \mathrm{g} / \mathrm{m}^{3}\right)\end{array}$ & $\begin{array}{c}\mathrm{BC} \\
\left(\mu \mathrm{g} / \mathrm{m}^{3}\right)\end{array}$ & $\begin{array}{c}\mathrm{PM}_{2.5} / \mathrm{PM}_{10} \\
\text { ratio }\end{array}$ & $\begin{array}{c}\mathrm{BC} / \mathrm{PM}_{2.5} \\
\text { ratio }\end{array}$ \\
\hline Min. & 132 & 74.6 & 16.8 & 0.51 & 0.09 \\
Max. & 401 & 345 & 41.3 & 0.97 & 0.29 \\
Mean & 269 & 183 & 29.7 & 0.78 & 0.17 \\
STD & 65.6 & 67.2 & 7.04 & 0.14 & 0.05 \\
Median & 264 & 164 & 29.0 & 0.81 & 0.17 \\
\hline
\end{tabular}

It has been found that the $\mathrm{PM}_{2.5}$ concentration is about three times higher than the BNAAQS. As the median value is less than the mean, hence it might be due to high concentration in few during sampling period. From the ratio of $\mathrm{PM}_{2.5} / \mathrm{PM}_{10}$, it was observed that about $78 \%$ of $\mathrm{PM}_{10}$ is $\mathrm{PM}_{2.5}$. It was also observed that about $17 \%$ of $\mathrm{PM}_{2.5}$ is $\mathrm{BC}$.

It was found (Table 2) that the concentrations of both $\mathrm{PM}_{10}$ and $\mathrm{PM}_{2.5}$ have increased almost 3.3 and 6.1 times, respectively than in December, 2001 to February, 2002. At present BC concentration has decreased than in December, 2001 to February, 2002. It might be due to CNG fuel uses in motor vehicles (Begum et al. 2006b).

Table 2. Comparison of $\mathrm{PM}_{10}, \mathrm{PM}_{2.5}$ and $\mathrm{BC}$ concentrations between 2001 - 2002 and 2012 . 2013 years.

\begin{tabular}{lllllll}
\hline \multirow{2}{*}{ Parameters } & \multicolumn{1}{c}{$\mathrm{PM}_{10}$} & $\mathrm{PM}_{2.5}$ & $\mathrm{BC}$ & $\mathrm{PM}_{10}$ & $\mathrm{PM}_{2.5}$ & $\mathrm{BC}$ \\
\cline { 2 - 6 } & \multicolumn{3}{c}{$2001-2002$} & & & $2012-2013$ \\
Min. & 31.9 & 11.9 & 5.05 & 132 & 75.0 & 16.8 \\
Max. & 12.4 & 50.1 & 14.9 & 401 & 345 & 41.3 \\
Mean & 80.5 & 29.8 & 8.64 & 269 & 183 & 29.7 \\
Stdev & 23.2 & 10.0 & 2.59 & 66.1 & 67.1 & 7.04 \\
Median & 77.9 & 27.5 & 7.92 & 264 & 164 & 29.0 \\
\hline
\end{tabular}

From the source apportionment results (Begum et al. 2014), it was found that the contribution of motor vehicles has decreased but the contribution of brick kiln including wood burning have increased almost 1.57 time than in 2001-02 period (Table 3). Other hand, the contribution from soil dust together with road dust have also increased same which is same as carbonaceous sources. Hence this soil dust (due to Fe) together with the black carbon from carboneous sources (brick kiln and wood burning sources) can absorb sun light. 
Table 3. Sources (Fine PM) from Rajshahi aerosol in different year.

\begin{tabular}{|c|c|c|c|c|c|c|c|}
\hline \multirow{3}{*}{ Sources } & \multicolumn{3}{|c|}{ 2001-2002 } & \multicolumn{4}{|c|}{ 2010-2012 } \\
\hline & \multirow[t]{2}{*}{$\%$} & Mass & $\mathrm{BC}$ or $\mathrm{EC}$ & \multirow[t]{2}{*}{$\%$} & Mass & $\mathrm{BC}$ or $\mathrm{EC}$ & Delta-C \\
\hline & & & $\mathrm{g} / \mathrm{m}^{3}$ & & \multicolumn{3}{|c|}{$\mu \mathrm{g} / \mathrm{m}^{3}$} \\
\hline Soil dust & 1.88 & 0.37 & 0.00 & 8.39 & 10.7 & 0.00 & 0.00 \\
\hline Road dust & 5.29 & 1.06 & 0.00 & 2.91 & 3.69 & 0.07 & 0.06 \\
\hline Sea salt & 13.89 & 2.77 & 0.00 & - & - & - & - \\
\hline CNG & - & - & - & - & - & - & - \\
\hline Brick kiln & 50.4 & 10.08 & 4.62 & 40.2 & 51.0 & 6.32 & 3.34 \\
\hline Wood burning & & & & 35.4 & 45.0 & 1.95 & 0.27 \\
\hline Motor vehicle & 28.5 & 5.69 & 1.18 & 9.80 & 12.4 & 3.44 & 0.31 \\
\hline Fugitive $\mathrm{Pb}$ & & & & 3.28 & 4.17 & 0.27 & 0.13 \\
\hline Reconstructed mass & & 20.0 & 5.80 & & 127 & 12.1 & 4.13 \\
\hline Measured mass & & 22.9 & 6.34 & & 149 & 13.0 & 5.68 \\
\hline
\end{tabular}

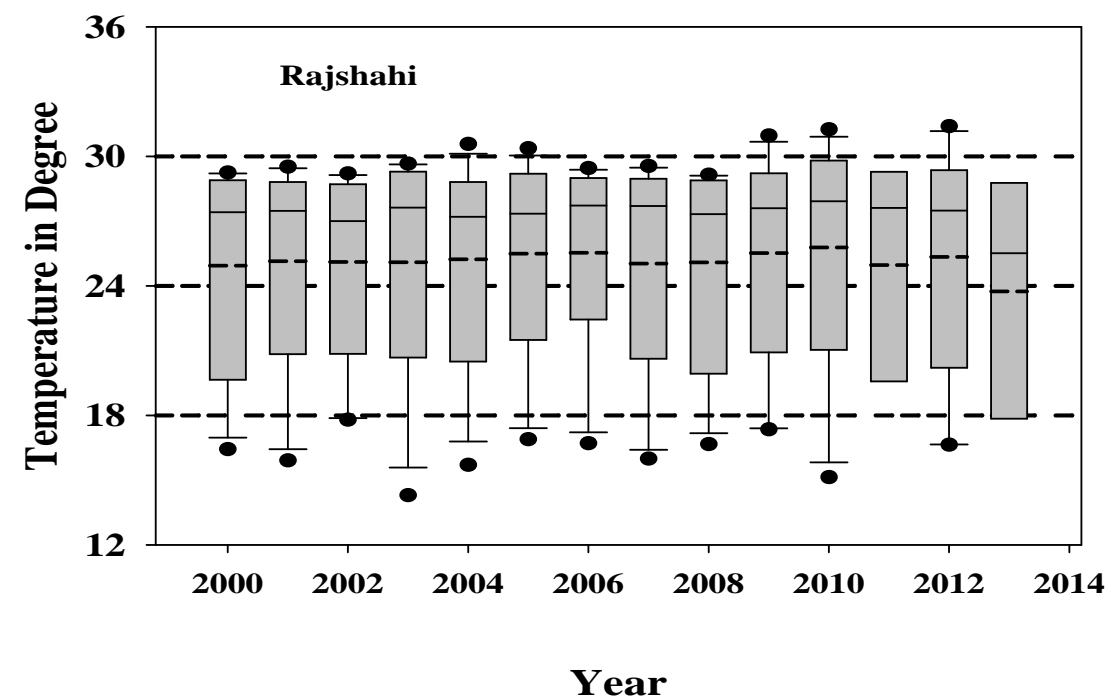

Fig. 4. Temperature profile at Rajshahi city during 2000 to 2013.

It was found from the meteorological data from 2000 to 2013, that the temperature increased almost 0.1 degree (Fig. 4). From Fig. 5 it would be found that the rainfall was high during 2000 to 2002. After 2002, the rainfall decreased. Therefore, the concentration of $\mathrm{PM}_{2.5}$ has increased due to contributions from soil dust including road dust, brick kiln and wood burning. Soil contains Fe which can absorb light and participate to increase the ambient temperature (Fig. 4). 


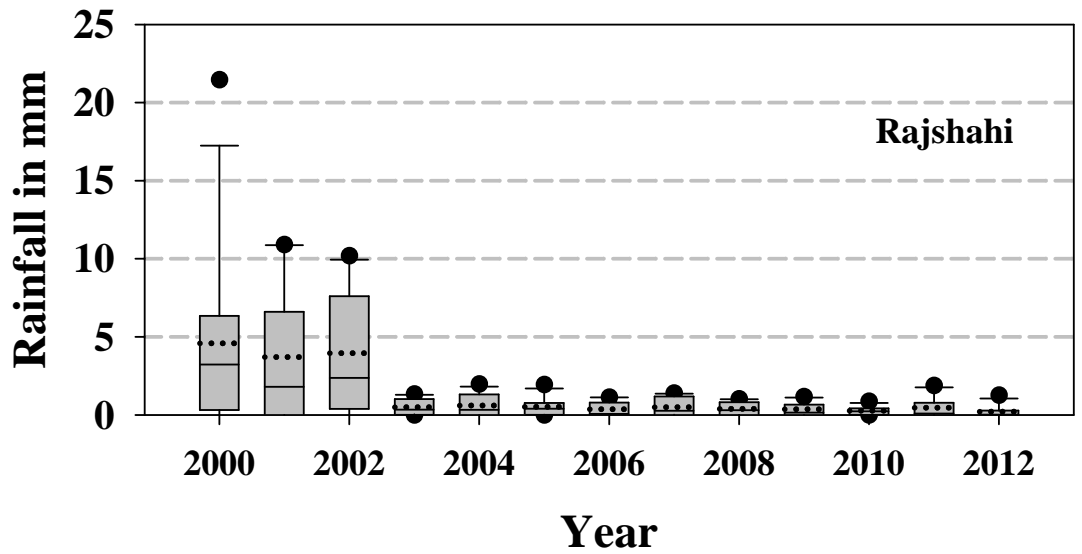

Fig. 5. Rainfall profile at Rajshahi city during 2000 to 2013.

\section{CONCLUSIONS}

As the concentrations of $\mathrm{PM}_{2.5}$ have increased due to soil dust particles, the government should address these dust particles and adopt policies for reduction from ambient air. But there is also long range transport (Begum et al. 2011) of soil dust particle, which increases the local pollutants during winter.

\section{ACKNOWLEDGEMENT}

The authors are grateful to the stuff of Chemistry Division, Atomic Energy Centre, Dhaka, for their assistance. They also acknowledge the authority of the Department of Environment permitting them for APM sampling from Rajshahi CAMS site.

\section{REFERENCES}

Begum, B. A., S. Akhter, L. Sarker and S. K. Biswas. 2006a. Gravimetric analysis of Air Filters and Quality Assurance in Weighing. Nuclear Science and Applications 15: 36-41.

Begum, B. A., S. K. Biswas and P. K. Hopke. 2006b. Impact of banning of Two Stroke Engines on airborne particulate matter concentrations in Dhaka, Bangladesh. J. Air and Waste Management Association 56: 85-89.

Begum, B. A., S. K. Biswas, G. G. Pandit, I. V. Saradhib, S. Waheed, N. Siddiquec, M. C. S. Seneviratne, D. D. Cohen, A. Markwics and P. K. Hopke. 2011. Long Range Transport of Soil Dust and Smoke Pollution in the South Asian Region. Atmospheric Pollution Research 2: $151-157$.

Begum, B. A., M. Nasiruddin, S. Randal, B. Sivertsen and P. K. Hopke. 2014. Identification and Apportionment of sources from Air Particulate Matter at Unban Environments in Bangladesh. British J. Applied Science \& Technology 4: 3930-3955.

Biswas, S. K., S. A. Tarafdar, A. Islam, M. Khaliquzzaman, H. Tervahattu and K. Kupiainen. 2003. Impact of unleaded gasoline introduction on the concentration of lead in the air of Dhaka, Bangladesh. J. Air and Waste Management Association 53: 1355-1362. 
Cooke, W. F. and J. J. N. Wilson. 1996. A global black carbon aerosol model. J. Geophysical Research 101(D14): 19395-19409.

Kehrwald, N. M., L. G. Thompson, Y. Tandong, E. M. Thompson, U. Schotterer, V. Alfimov, J. Beer, J. Eikenberg and M. E. Davis. 2008. Mass loss on Himalayan glacier endangers water resources. Geophysical Research Letters 35: L22502.

Koelmans, A. A., T. O. J. Michiel, G. Bucheli, D. Thomas, C. M. V. N. Paul and O. Gustafsson. 2006. Black carbon: the reverse of its dark side. Chemosphere 63: 365-377.

Kundu, P. C., B. Tarafder, S. R. Hayat, M. R. U. Mollah and M. Nasiruddin. 2006. Roadside vehicle emission testing program in Dhaka AQMP-DoE: TECDOC NO-01/06.

Penner, J. E., H. Eddieman and T. Novakov. 1993. Towards the development of a global inventory for black carbon emissions. Atmospheric Environment 27: 1277-1295.

Salam, A., H. Bauer, K. Kassin, S. M. Ullah and H. Puxbaum. 2003. Aerosol chemical characteristics of a mega-city in Southeast Asia (Dhaka, Bangladesh). Atmospheric Environment 37: 2517-2528. 